University of Wollongong

Research Online

Faculty of Business - Papers (Archive)

Faculty of Business and Law

$1-1-2013$

Lost in translation? An actor-network approach to HRIS implementation

Kristine Dery

University of Sydney

Richard Hall

University of Sydney

Nick Wailes

University of Sydney

Sharna L. Wiblen

University of Sydney, swiblen@uow.edu.au

Follow this and additional works at: https://ro.uow.edu.au/buspapers

Part of the Business Commons

Research Online is the open access institutional repository for the University of Wollongong. For further information contact the UOW Library: research-pubs@uow.edu.au 


\title{
Lost in translation? An actor-network approach to HRIS implementation
}

\author{
Abstract \\ Available evidence suggests that the adoption of IT-enabled Human Resource Information Systems \\ (HRIS) has not produced the widely predicted transformation of Human Resources (HR) to a strategic \\ business partner. We examine the relationship between HRIS and the HR function by applying actor- \\ network theory (ANT) to an HRIS implementation project. The focus on how actor networks are formed \\ and reformed during implementation may be particularly well suited to explaining why the original aims of \\ the HRIS can be displaced or lost in translation. We suggest that the approach afforded by ANT enables \\ us to better understand the ongoing and contingent process of HRIS implementations. \\ Disciplines \\ Business \\ Publication Details \\ Dery, K., Hall, R., Wailes, N. \& Wiblen, S. (2013). Lost in translation? An actor-network approach to HRIS \\ implementation. Journal of Strategic Information Systems, 22 (3), 225-237.
}

This journal article is available at Research Online: https://ro.uow.edu.au/buspapers/939 


\section{Lost in Translation? An actor-network approach to HRIS implementation}

\section{Introduction}

In recent years increased attention has focused on the contribution that human resource information systems (HRIS) can make to the transformation of the human resource function in organizations. Despite the promises of vendors, the available evidence suggests that in the vast majority of cases IT-enabled HRIS have not helped produce a wholesale transformation of the HR function away from routine processing and compliance and towards the strategic business partner role that many were expecting (Bondarouk \& Ruël, 2012; Kinnie \& Arthurs, 1996; Parry \& Tyson, 2011). In this paper we examine the contribution of contemporary debates in the information systems literature, and particularly the application of actor-network theory (ANT) to IS implementations, seeking to enhance our understanding of HRIS implementations and their impact on the transformation of the HR function. Drawing on a detailed case study of an HRIS implementation at a large manufacturing firm, we argue that examining changes in the actor-networks within which HRIS are implemented provides valuable insights into why the strategic ambitions of the HR function are often "lost in translation" during the HRIS implementation process.

The paper is structured as follows. The first section briefly reviews the debates and evidence about HRISs in the human resource management literature. It demonstrates that despite the promise, there is little evidence to suggest that HRIS implementation has enabled the transformation of the HR function away from routine processing and towards a more strategic orientation. In the second section we argue that this apparent paradox of HRIS can in part be explained by the overly simplistic view of the relationship between technology and organization that informs many of the studies of HRIS. Drawing inspiration from contemporary debates in the information systems literature, we outline the contribution that we believe a more sophisticated and nuanced view of technology in organizations, drawn from ANT, can make to the study of HRIS and strategic HRM. The remainder of the paper focuses on a detailed case study of an HRIS implementation at a large manufacturing firm and examines the extent to which this ANT-based approach provides insights into the implementation process and its outcomes. The final section discusses the broader 
implications of our findings for understanding the relationship between HRIS and the strategic transformation of HR.

\section{The paradox of HRIS: HRIS in the Human Resource Management literature}

Since the mid 1980s there has been a growing body of evidence that Human Resource Management (HRM) related practices have the potential to make a significant contribution to organizational performance (for a review see Strohmeier, 2007, 2009). On the basis of this evidence it has been widely argued that to effectively contribute to creating sustainable competitive advantage the human resource function needs to move from focusing on routine administrative and compliance issues to a strategic partnering focus (Becker, Huselid, \& Ulrich, 2001; Huselid, 1995; Paauwe \& Boselie, 2005; Ulrich, 1997). During the 1990s, the emergence of increasingly sophisticated HR related packaged software solutions, both standalone and as modules of larger enterprise systems, seemed to offer HR professionals the tools they needed to help achieve this transformation and to enhance their contribution to organizational performance. It is in this context that the study of the impact of Human Resource Information Systems (HRIS) is of direct significance to ongoing debates about the strategic transformation of HR.

While there are a range of competing definitions of HRIS (Ball, 2001; Hyde \& Shafritz, 1977; Kavanagh \& Thite, 2009), there is general consensus that a HRIS is a system used to acquire, store, analyze, retrieve and distribute pertinent information regarding an organization's human resources (Bondarouk \& Ruël, 2008; Hendrickson, 2003) and that it includes hardware, software, people, policies, procedures, and data (Kavanagh, Gueutal, \& Tannenbaum, 1990). The study of HRIS can be regarded as a distinct area of research within the e-HRM domain (Bondarouk \& Ruël, 2009; Strohmeier, 2007; Voermans \& Van Veldhoven, 2007). HRIS is an information system that is largely associated with the HR function and where the primary users of these systems and the information generated are individuals employed as part of this function, whereas e-HRM can be considered 'the technical unlocking of HRIS for all employees of an organization' (Ruël, Bondarouk, \& Looise, 2004b:17) and is 
concerned with 'all possible integration mechanisms and contents between HRM and Information Technologies aiming at creating value within and across organizations for targeted employees and management' (Bondarouk \& Ruël, 2009:507). We therefore view HRISs as a sub-domain of e-HR and our study thus focuses on the technology, people, policies, procedures and data used to effectively manage the HR function in the organization. Our focus on HRIS as a distinct sub-domain of e-HRM is also a reflection of how the organization and key actors in our case study choose to describe and delineate their project.

It is important to note that while definitions of HRIS include people, policies, practices and hardware, in reality much of the debate in the HR field has focused on the increased functionality of HR related packaged software solutions. It has been argued that, in their current form, these solutions have the potential to facilitate the shift of the HR function away from focusing on routine administrative functions and to play a more strategic business-partnering role in at least three respects. First, by automating and devolving many routine HR tasks to line management, HRIS may provide HR professionals with the time needed to direct their attention towards more business critical and strategic level tasks, such as leadership development and talent management (Lawler \& Mohrman, 2003; Morley, Gunnigle, O'Sullivan, \& Collings, 2006). Second, HRIS's can help drive the 'modernization' of HR departments (Bondarouk \& Ruël, 2009) and the implementation of 'transformational' (i.e. strategic) HR practices (Bondarouk, Ruël, \& van der Heijden, 2009; Ruël, Bondarouk, \& Looise, 2004a). These typically include the outsourcing of HR (Barron, Chhabra, Hanscome, \& Henson, 2004; Morley et al., 2006; Ruël et al., 2004a), or the creation of Human Resource Shared Service Centers (Farndale, Paauwe, \& Hoeksema, 2009). Finally contemporary HRIS's make it possible for HR professionals to generate real time data and metrics on HR related issues that can be used to support strategic decision making (Lawler, Levenson, \& Boudreau, 2004; Lengnick-Hall \& Moritz, 2003).

However, despite the potential benefits highlighted in this research stream, and promoted strongly in HRIS packaged software solutions vendor marketing material and in a range of recent studies (Kavanagh \& Thite, 2009; Ruta, 2009; 
Strohmeier, 2009; Towers Perrin, 2008), there is limited evidence to suggest that HRIS adoption has produced widespread transformation of the HR function. Early surveys on HRIS usage suggested that these systems were used predominantly to automate routine tasks and "to replace filing cabinets" (Kinnie \& Arthurs, 1996; Martinsons, 1994). Lawler et al (2004) noted that that while $80 \%$ of respondents in their study had an HRIS, less than $40 \%$ used them to produce data that was used for strategic decision-making. While more recent research shows greater use of HRIS in support of strategic decision making by HR (see Hussain, Wallace, \& Cornelius, 2007; Ngai \& Wat, 2006), they continue to show that the impact of HRIS on HR differs across organizations, with a small (but growing) proportion of organizations using HRIS in a highly strategic fashion and the vast majority using HRIS simply to replace manual processing and to reduce costs (Bee \& Bee, 2002; Brown, 2002; Haines \& Lafleur, 2008; Strohmeier, 2007).

\section{Towards an actor-network based view of HRIS}

In our view, the apparent paradox of HRIS- that despite their promise HRIS implementations often fail to enable the transformation of the HR function- in part reflects the overly simplistic view of the relationship between technology and organization that pervades much of the debate about these systems in the HR literature. We argue that if HR scholars and practitioners are to gain a better understanding of relationship between HRIS and the strategic potential of the HR function, they need to adopt a more nuanced and sophisticated view of the interplay between technology and organization. In short, we suggest the need for a much deeper engagement with contemporary IS debates and in particular those that examine the mutually dependent relationships between technology and the organizational context in which it is deployed.

Much of the current research on HRIS in the HR literature adopts a determinist position and treats technology in functionalist terms, seeking to explore its impact and potential for enhancing the HR function (for a review of the different approaches see Strohmeier, 2009). In this respect it is consistent with Dewett and 
Jones' (2001) call for research that explores how IT contributes to firms' competitive advantage, improving organizational performance and the impact of IT on processes, decision-making and behaviour. In this view HRISs are seen to be tools with the capacity to improve business processes and HR functional efficiency and strategic effectiveness and the goal of HRIS implementations is the transformation of the HR function, and in particular, the realization of their strategic ambitions. Explanations for differences in the impact on HRIS on the strategic role played by HR have, on occasion, drawn on the wider IS literature, especially from the literature on ERP implementation. Thus, for example, there are a number of studies that have attributed the limited impact of HRIS on the strategic role played by HR to factors such as insufficient budget, lack of top management support, problems with user acceptance, lack of support for HR users, coordination problems and the impact of competing executive priorities (see Grant, Dery, Hall, Wailes, \& Wiblen, 2009; Kovach \& Cathcart, 1999). While these studies provide some important insights into a range of factors that can influence the impact of HRIS on HR, we argue that there is much to be gained from a deeper engagement with the growing body of IS literature that draws attention to mutually dependent relationship between organization and technology (Orlikowski \& Scott, 2008).

In particular we are interested in identifying and illuminating an account of a HRIS implementation to provide a more compelling and holistic understanding of the challenges in enacting the strategic functionality of such systems. In doing so we demonstrate that the potential of the HRIS to strategically transform the HR function may be distinct and separate from the strategic ambitions of the HRIS implementation project itself. It is for this reason that we are drawn to aspects of Actor Network Theory (ANT).

Since Walsham's (1995) call to explore the role of interpretivism in information systems (IS) research, ANT has informed a number of studies of IS implementation. Examples include studies of the implementation of computer aided ambulance dispatch systems (McGrath, 2002), computerized baggage handling system in a major US airport (Mahring, Holmstrom, Keil, \& Montealegre, 2004), health information systems (Cho, Mathiassen, \& Nilsson, 2008; Cresswell, Worth, \& 
Sheikh, 2010) inter-organizational information systems in a major Spanish seaport (Rodon, Pastor, Sese, \& Christiaanse, 2008) an ICT enabled development project in Latin America (Andrade \& Urquhart, 2010) and in relation to the deployment of CAD software across a number construction firms (Harty, 2010). Particularly notable are recent contributions by Elbanna $(2008,2010)$ in which she uses an ANT framework to explain both project drift and the impact of other projects on the IS implementation, two issues that are relevant to the study of HRIS implementation and are evident in the case study we discuss below.

While we are aware that aspects of ANT remain controversial and contested, we believe that a number of its key concepts are useful in helping us understand the HRIS implementation process and its relationship with the often unrealized strategic aspirations of the HR function. ${ }^{1}$ In particular, using the core ANT concept of translation we argue that there is a tendency for the strategic aims of the HR function to become "lost in translation" through the HRIS implementation process. In this section we very briefly summarize some of the key features of an ANT approach and, drawing on a range of studies that have applied this framework to IS implementations, identify how it can help inform the study of HRIS.

Perhaps the most well known, and controversial feature of ANT is its treatment of actors according to generalized symmetry, meaning that little or no distinction is drawn between human and non-human actors. Latour (1991:117) 1991 (p117) argues that: "Contrary to the claims of those who want to hold either the state of technology or that of society constant, it is possible to consider a path of an innovation in which all the actors co-evolve." Thus studies that adopt an ANT framework focus on the formation of heterogeneous actor-networks that may include amongst other things people, objects, technologies, agents and organizations (Tatnall \& Gilding, 1999)(Tatnall and Gilding, 1999). Far from seeing actor-networks as fixed and unchanging, an ANT perspective regards actor-networks as subject to constant pressures for change both because of the ongoing potential for changes in the actors in

\footnotetext{
${ }^{1}$ For a critique of ANT and its application to the study of organizations see Whittle and Spicer 2008. For a countervailing view see Alcadipani and Hassard 2010. The approach that we adopt here, following Andrade and Urquart (2010), differs from the original conception of ANT because of our focus on situating actors in their contextual background.
} 
the network and the relations between them (Callon, 1986)(Callon, 1986)). For this reason, many studies related to ANT focus on the process of actor-network formation and reformation or translation (Callon, 1986; Law, 1992)(Callon, 1986, Law,1992).

One influential depiction of this translation process identifies four moments of actor-network formation: problematization, interessement, enrollment and mobilization (Callon, 1986). During problematization the network initiator frames an opportunity and persuades other actors, despite their diverse interests, to devote resources to developing a solution to the problem. Interessement is the process by which the problematization is confirmed and other actors become interested in the proposed solution, thereby disrupting competing associations. This creates the conditions for the third moment of actor-network formation, enrollment. Enrollment involves 'the definition of roles of each of the actors in the newly created actornetwork and ... involves a set of strategies through which the initiators seek to convince other actors to ... be an active part of the whole project' (Mahring et al., 2004). The final moment of translation is mobilization in which the actor-network becomes durable and the relations between actors become irreversible allowing the network to behave as if it were a single actor, or to use Latour's (1987) phrase, a black-box. While this presentation of translation implies it is linear and sequential, as Elbanna (2008:90) points out, ANT proponents regard successful translation of an idea or project into a stable actor-network as a rarity and see network formation as a highly fluid and contested process.

In our view an ANT approach provides a promising framework for examining the relationship between HRIS implementation and the transformation of the HR function. Because ANT does not privilege either the social or the technical, this framework makes it possible for us to simultaneously consider the social and technical elements of HRIS implementations. Many of the predictions made about the impact of HRIS on the HR function, both positive and negative, assume that these technologies have determinate consequences for the organizations that adopt them (for a review see Strohmeier, 2007, 2009). This technologically determinist view appears limited in its capability to explain the differences in the impact of HRIS on the HR function, and ignores the possibility that the same technology can be used in 
different ways in different contexts (Orlikowski, 2000) and that implementation complexity often results in unintended consequences (Hanseth, Ciborra, \& Braa, 2001). As a number of studies have noted an ANT framework is particularly well suited to helping explain why a particular technology may be adopted in a different way across different organizations - a key issue in the study of HRIS (see, for example Harty, 2010).

Recently there have been calls in the broader e-HRM literature for studies that distinguish between implementation phases, that pay particular attention to various levels of analysis and which go beyond focusing on just the role of HR professionals and employees, and consider the role of other relevant actors, such as line managers, responsibility units, and consultants (Strohmeier, 2007; Strohmeier \& Kabst, 2009). Our view is that an ANT approach can play a role in answering this call.

By focusing on the formation and reformation of actor-networks, an ANT framework implies that HRIS implementations take place through an ongoing series of events and detours rather than assuming that the implementation of technology is a discrete project (Tatnall \& Gilding, 1999). (Tatnall and Gilding, 1999) And the focus on actor-networks allows the analysis to identify the role of different types of actors, from individuals, teams and departments to the organization and technological artifacts and to examine the interplay between HR and other relevant actors.

Specifically we think that a focus on how actor-networks are formed and reformed during the implementation process may be particularly well suited to explaining why the original aims of HRIS implementation, and particularly the desire of the HR function to deploy these systems in support of their strategic ambitions, may often be displaced. Using an ANT framework, Elbanna demonstrates that it is the process of shifting from one network to another that can explain "why companies implementing the same packaged ERP system achieve different results, despite the initial perception that introducing the same standard ERP system between organizations should follow a rather straightforward and predictable trajectory" (2008:95). She also demonstrates that in many cases IS implementations take place in environments in which there are a range of ongoing projects and that as a result "IS 
projects are in a constant negotiation of boundaries as different organizational actors emerge to renegotiate the previously set boundaries" (Elbanna, 2010:48).. In our view both of these factors, the tendency for projects to drift and the potential for other organizational projects to impact on IS implementations, are likely to be important in helping explain why the strategic ambitions of the HR function are so often lost in translation during the HRIS implementation process.

\section{Research Methodology}

\subsection{Research approach}

We examine the contribution of ANT to the analysis of HRIS implementation and its impact on the HR function using an interpretative case study (Walsham, 1995). A longitudinal single site case study enabled systematic collection of information about social settings, events and individuals (Berg, 2009) such that the authors could '...study the experiences of real cases operating in real situations' (Stake, 2006:3). In addition, this approach allowed us to track and examine changes to the HRIS as well as within the organization and the HR function (Pettigrew, 1990). This was essential to the research aims and enabled the inclusion of both real-time and reflexive experiences of the selection, design and implementation of a new HRIS. We studied the processes through which the organization and its key actors evaluated the legacy HRIS, considered alternatives, deployed related arguments, selected the new HRIS and used its implementation to achieve goals other than the 'rational' and functional goals of HR strategic transformation. This allowed us to examine whether and how changes in the actor-network during the HRIS implementation process impacted on HR's capacity to deliver strategic value to the organization.

\subsection{Data collection and analysis}

Data associated with the case study was gathered over a four-year period, between 2008 and 2011 and included semi-structured interviews, observations of the HRIS in use, internal company documentation and publically available information 
about the company and its HRIS implementation. In total 32 semi-structured interviews were conducted over this 4 year period with at least two interviewees present at each interview, with one interviewer consistently present across all interviews.

The data and other sources of text was then subjected to a detailed and systematic examination and interpretation using content analysis (Berg, 2009). This process involved coding at two levels. At the first level, we applied a lexicon of terms that emanated from the data itself and which related the HRIS implementation and strategy. It was during this process that the themes such as risk, structure, IS management, and IS skills were revealed. At the second level we applied a priori constructs (Eisenhardt, 1989) which were grounded in the existing literature. For example, we identified statements that related to the HRIS implementation process, HR strategy, business strategy and alignment. The key themes that emerged from this stage of analysis were explored, discarded and further refined (Miles \& Huberman, 1994).

Each iteration of the content analysis was undertaken by at least two researchers who contributed their own double hermeneutic interpretation of manual notes, interview transcripts and additional data. As these themes emerged and coalesced around intervals in the story we were able to identify junctures where there were shifts in the alliances between actors, the relative positioning of the actors themselves relative to the decision-making processes, and the ways in which considerations were being prioritised around the HRIS.

The analysis made it possible for us to construct a story of the HRIS selection, design and implementation built using the text generated by the actors themselves. In this way we were able to capture contested positions, alliances and the process of negotiation of spaces within the broader organizational context. This practice of storytelling is consistent with event history (Van de Ven, 1989; Van de Ven \& Poole, 1990) and we were careful to document the process of implementation as well as who did what and when, as well as reflect upon and note which actor was being represented during the process. This focus on event history is consistent with the 
approach adopted by others who have applied an ANT framework to the analysis of IS implementations. By capturing and analysing the data as a chronological story we question both the organizational context at the same time as illuminating how the actors "define their respective identities, their mutual margins of manoeuvre and the range of choices which are open to them" (Callon, 1986:4).

\subsection{The case of $M F C$}

The case study organization is a large, diversified Australian manufacturing company, which we refer to in this article as MFC. During the course of the research MFC replaced a highly customised standalone HR system with the HR modules associated with the firm's ERP system - SAP R/3. MFC is a leading Australian manufacturing company with operations in Australia, Asia and New Zealand that has been operating for 155 years. Currently, MFC and its subsidiaries, employ more than 7,200 employees across five main businesses ranging from agricultural to building products.

In recent years, MFC's strategy has focussed on the simplification of the conglomerate structure primarily through the sale of business units, but also through the centralisation and standardisation of business functions. This strategy was largely driven by feedback from the market analysts that the conglomerate structure was too complex for investors and was compromising the market value of the organization. By the beginning of 2011 almost $\$ 2$ billion of assets had been sold and the organization positioned in the market as two separate and more focussed businesses "each with the flexibility to pursue their own distinct strategies" (Chairman's address to shareholders, 2011). This restructuring process enabled MFC to strengthen its balance sheet, retire all debt, return more than $\$ 800$ million to shareholders through dividends and share buy-backs and capital return, and establish a simplified structure for global growth. In 2008, as part of the series of initiatives designed to facilitate this corporate strategy, MFC commenced a process of evaluating (with a view to upgrading or replacing) its legacy HRIS.

\section{The implementation of a new HRIS at MFC}




\subsection{The Legacy HRIS}

In 1986 MFC invested in its first automated HR system in response to the need to automate the recruitment and training processes of one of their major manufacturing businesses. Frontier's "CHRIS" technology was selected and implemented by October 1986 primarily to gather information on wage employees, manage annual leave administration, streamline the salary review process, log licences and certificates of qualified staff, and to manage aspects of health and safety. Frontier CHRIS was a stand-alone IS that drew data from a range of organizational databases to populate dedicated HR software for reporting purposes. The implementation program was managed by MFC using in-house dedicated resources and expertise based in the HR department. Further development and management of the system was supported by the HRIS team which was completed by the addition of an IS technician from Frontier who joined MFC late in 1986. As the HRIS Director explained, MFC took the Frontier CHRIS system and adapted it to their existing HR processes:

fairly early in the piece, we had bought the CHRIS system from Frontier lock, stock and barrel. So we had the source code. And very early in the piece, one of Frontier's technical people, who was assisting me with the implementation, decided that he didn't want to work for Frontier any more, he wanted to work for us.

The HRIS technical team (3 fulltime staff) were located in the Human Resources department rather than in Business Information Systems (BIS) as it was considered that the dedicated focus of this team working with the stand-alone Frontier CHRIS system would deliver more specific capabilities for the HR function.

In 1987 a Frontier CHRIS upgrade incorporated payroll and was designed to eventually centralise MFC's 63 different payroll systems into a single system and then to add analytical and reporting functionality that would potentially enable both HR and business unit managers to manage their people more effectively. Increased functionality requirements, along with the need for broader accessibility, resulted in the introduction of a web-based system- 'WebCHRIS'- in 2008. Over time with upgrades and modifications (made possible through the ownership of the source 
codes) to meet HR process requirements, the CHRIS system was barely recognisable as the Frontier vendor product and had essentially become an MFC proprietary system.

At the beginning of this research project in June 2008, approximately $65 \%$ of MFC staff had access to WebCHRIS via their own desktops, additional on-site kiosk systems had been established for factory and site-based staff, and access to the system via MFC laptops was available for senior and middle management. Table 1 summarises the functionality of the system by 2008 . While the system was largely traditional (delivering standard $\mathrm{HR}$ data such as staff records and regulatory information) and transactional (on-line HR transactions such as leave applications, time sheets, expenses), it had the potential to provide strategically useful data for projections and decision-making. HR professionals, and business unit managers, made extensive use of specialised reports produced by the HRIS.

Table 1: Functionality of the MFC WebCHRIS 21 (2008)

\begin{tabular}{|c|c|c|}
\hline $\begin{array}{l}\text { Traditional HR Services } \\
\text { (data posting services) }\end{array}$ & $\begin{array}{l}\text { Transactional HR Services } \\
\text { (data activity capabilities) }\end{array}$ & $\begin{array}{l}\text { Transformational } \\
\text { (Strategic) HR Services } \\
\text { (strategically aligned } \\
\text { metrics with analytical } \\
\text { capabilities) }\end{array}$ \\
\hline 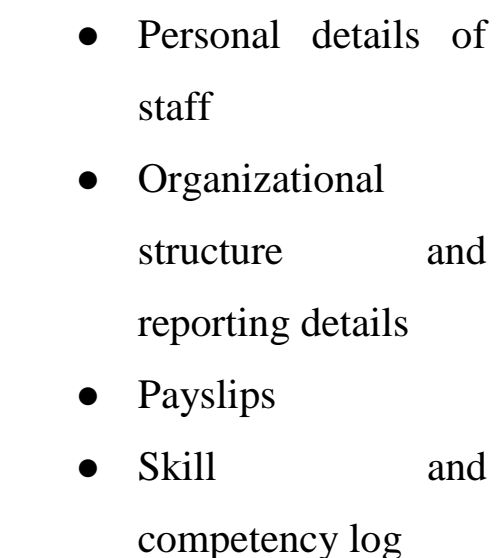 & $\begin{array}{l}\text { - Leave applications } \\
\text { and approvals } \\
\text { - Payslips deductions } \\
\text { - Training } \\
\text { applications and } \\
\text { bookings } \\
\text { - Payrolls } \\
\text { - Overseas travel }\end{array}$ & $\begin{array}{l}\text { - Training and } \\
\text { development } \\
\text { needs assessments } \\
\text { and projections } \\
\text { - HR planning and } \\
\text { reporting e.g.: } \\
\text { turnover, payroll } \\
\text { projections, }\end{array}$ \\
\hline
\end{tabular}




\begin{tabular}{|c|c|c|}
\hline $\begin{array}{l}\text { - Job descriptions and } \\
\text { categories } \\
\text { - Notifications to staff } \\
\text { - Legislative } \\
\text { requirements and } \\
\text { awards } \\
\text { - Telephone } \\
\text { directories }\end{array}$ & $\begin{array}{l}\text { applications and } \\
\text { monitoring } \\
\text { - Workers } \\
\text { compensation and } \\
\text { reporting } \\
\text { - Licence expiry } \\
\text { - Absence reporting } \\
\text { - Performance } \\
\text { management } \\
\text { system } \\
\text { - Induction program }\end{array}$ & $\begin{array}{l}\text { annual leave } \\
\text { reporting, } \\
\text { superannuation } \\
\text { - } \\
\text { Risk management }\end{array}$ \\
\hline
\end{tabular}

\subsection{The Problematization of Risk and the Positioning of SAP as the Solution}

Over time the CHRIS system had been so highly customised by the MFC HRIS team to specifically meet the complex HR needs of each division and the organization as a whole, that it could no longer be supported in any capacity by Frontier. The HRIS team delivered a valued system to multiple users organizationwide. The new Group HR Director, who was appointed in 2008, described the HRIS as follows:

I think the thing that struck me about the system is, given the length of time that it's been in the company, the extent of what the team here have got it to do is pretty impressive... the company has been pretty well served from something that has been done in-house and tapered according to the (organization's) needs.

The HRIS Director had been with the company for more than 30 years and was primarily responsible for the implementation of MFC's first HRIS. Since that 
time the HR function had assumed primary responsibility for the HRIS and its upgrades. The HRIS team was also long serving, the newest member of the team having been employed seven years ago. All customisation, upgrades, training and support were undertaken by this team with minimal contact with BIS other than the provision of hardware.

Despite organizational support for WebCHRIS, changes in the overall corporate strategic direction meant that there were significant challenges associated with maintaining it. Firstly, Web CHRIS was largely built on the personal knowledge of the HRIS Director and his two programmers. The imminent retirement of the HRIS Director raised questions around the vulnerability of the system and the capacity to sustain it after his departure, Secondly, the existing HRIS structure was complex and relied on a number of "add-on" systems to deliver HR services. These included: a time and attendance system (Chronos); a domestic travel expense approvals system (Promaster); Employee Self Service (Pay Global); financials (SAP); recruitment (People PageUp); psychological testing (SHL and ACER); and recruitment media advertising (Ad Control). While these systems were delivering very effective HR services they relied heavily on the small HR team's knowledge to manage and maintain them. Thirdly, and crucially, senior management argued that MFC's new business strategy necessitated a review of the HR systems:

I guess the challenge for MFC now is what the world looks like going forward and whether the staff within the current operation are the necessary fit to what the mission looks like going forward. (Group HR Director)

It was against this backdrop that the Group HR Director initiated a process to evaluate the HRIS and make recommendations on its future development. Although members of HR were part of the steering and evaluation committee who eventually selected SAP as the replacement system, it was apparent that they (including the HRIS Director) preferred to upgrade to Frontier's WebCHRIS 21. This preference was associated with their existing knowledge of, and skills related to, WebCHRIS 21, their familiarity with screens and processes, and their overall satisfaction with the 
system. When asked about the prospect of a new HRIS one HR Executive commented:

It's new, I suppose it's like learning how to drive a left handed car or something. So I need to sort of get completely out of my comfort zone into this. Yeah I mean it will be very interesting, I like that sort of stuff. But yeah we need to make it useful for the businesses. (HR Executive).

The decision to replace CHRIS with SAP was reached with the help of a specialised HRIS external consultant, a steering committee (consisting of the Group HR Director, CIO, General Manager HR, Business Service Centre Manager, and a Business Unit CFO) and an evaluation user team (consisting of representatives from HR including the HRIS Director, Learning and Development, Occupational Health and Safety and Payroll). While HR functionality purportedly factored in the decisionmaking process of the user team, the current and future needs of the organization were clearly prioritised by the steering committee:

So at the end of the day we have taken more consideration of the financial strategic uses of the system in areas where we haven't used it before. So there's been a high degree of importance given to strategic over administrative functionality. (Group HR Director).

While MFC's primary explicit motivation in replacing their HRIS was to minimise the risk associated with the in-house system managed by HR, management readily acknowledged that the new HRIS needed to be able to deal with change. While SAP was determined to have increased capabilities in the several areas (learning and development, succession planning, talent management, report generation, recruitment, performance management, manager self-service, training and inductions, extraction of financial data and dealing with expense claims), the critical driver for the selection of this system was the global recognition of the SAP brand and that its capacity to enable process standardisation throughout the organization.

The selection of SAP also meant that the management of the HRIS could be shifted from HR and placed in the BIS team where there was existing SAP expertise, 
thus enabling MFC to leverage SAP support resources and manage the system more easily within the corporate IS strategic goals. The clear implication of the selection of SAP was that this IS platform would be more attractive to a future purchaser of any of the divisions. Given that IS costs are recognised as one of the highest hidden costs in mergers and acquisitions, any moves to minimise these costs were likely to be favoured by senior management. The introduction of SAP also presented an opportunity for the Group HR Director and senior management to restructure, consolidate and standardise processes, across the organization.

While challenges were identified in the transition to SAP, HR anticipated that most of these could be overcome with training and a range of change management programs. Interviewed at the time of the decision, the HRIS Director anticipated a degree of adjustment but didn't anticipate that this would impact the HR function itself or where the HRIS was located.

We will have a far greater change management aspect of the implementation than we would have if we'd gone with Frontier (CHRIS)... But I don't see huge changes within the HR function itself... we don't have at the moment any SAP HRIS skills in the organization. We're planning to develop these within the present team who have been working on CHRIS.

BIS, also anticipated some data migration issues and the need for specialist training on the HR module, but given that they already had substantial SAP expertise, the change-over would be minimally disruption and offered opportunities to centralise help desks and expand existing skills. An external consultant (XTD) was engaged to provide the additional specialist IT resources required to make the transition and to advise MFC on change management practices. XTD was a small IT consulting firm that specialised in SAP R/3 and had extensive HRIS experience. This firm was selected as a partner because it had a reputation for adopting a cost-effective, standardised approach to SAP implementation, as opposed to the clean-canvas, bottom-up approach promoted by other consulting firms.

\subsection{Implementation of the new HRIS and the re-structuring of HR}


By mid 2009 MFC was getting ready to go live with the new SAP system, however, there was a large piece of the HR puzzle that began to become problematic as they considered their implementation strategy. For the past 30 years MFC had a centralised payroll department located in a rural location many miles from Head Office. There was no reason for this location, other than historic preferences and there was a team of 10 payroll clerks all with long company service and high levels of skill and knowledge of the MFC business. Payroll was a complex activity with a multiplicity of union- based collective agreements across 3 countries and 5 businesses. The payroll clerks were also very experienced in using the CHRIS system, had been very involved in the development and re-development of the functionality of CHRIS. Under the new strategic direction for MFC it became clear to the Group HR Director that centralisation of payroll was imperative (for cost purposes) and that the SAP implementation represented a golden opportunity to relocate this function to Head Office. Clearly payroll was the most critical element of the new HRIS to get right and so this left MFC with some significant challenges.

I'll always say you have to get paid. You have to pay people. That's why, throughout this, I set little hurdles. Pay people becomes a priority. Then it goes from there - have people being able to put leave in; have people being able to look at their team through MSS and - the finance piece was probably as equally important as payroll, just about, to get right. (Senior HR Executive).

The decision to build a new payroll department resulted in all the existing payroll clerks taking redundancy payouts and a new SAP skilled team employed in Head Office. While MFC avoided having to retrain existing staff, they faced the potential downsides of losing many years of organizational knowledge at the expense of gaining SAP technical expertise. Although this move addressed all the strategic considerations of the organization, it was potentially problematic from a functional perspective with new payroll staff having no understanding of MFC's business and 
HR functionality. While new payroll staff spent some time during handover with mentors from the previous payroll team, it was impossible to transfer all knowledge.

When (we) look back on that, it was a highly challenging 12 months in that regard because we actually did have to manage across some highly emotive periods. I don't actually think that's all to do with the SAP thing though. Some of that was to do with the move. Some of that was "why didn't we choose to retrain those people in SAP and leave them there?" There was all those organizational decisions which come into it as well. (HRIS Director).

By mid 2010 the SAP HRIS was embedded into the organization and while the old system was still available for historical data access, it was no longer accessible for current use. The transition, however, had not been smooth and there was significant resistance from users as a result of loss of functionality and the adaptation to a new technological environment. While management could see the benefits of risk minimisation and a more centralised, standardised IT platform, for the user it was hard to come to terms with a new system that gave them less functionality, was more difficult to use and appeared to result in the prioritising of SAP skills over organizational knowledge:

Yeah, I think there's no question that the average user who's using the employee self service would say it's inferior - SAP's inferior to CHRIS because the guys had built a really impressive self service within CHRIS. It's as good as any I've ever seen. (Group HR Director).

"It (CHRIS) had satisfaction ratings over 80 per cent consistently. The next one (SAP) was lucky to get 50. ..... You can't take something that's so successful and so loved, for whatever reason, and then replace it with a big monster that you're going to have to build and get people on board with. There's always going to be a challenge." (BIS Executive).

\subsection{Stabilization of the New Corporate Strategy, Structure and HRIS}


During the course of the implementation, discussions with potential buyers of part of MFC were taking place and as a result the likely shape of the future organization was starting to form. This had further implications for decisions around the new HRIS and the organizational structure. While these plans were being discussed at a senior management level, they were clearly confidential and thus the criteria for the decision-making was not always clear to the general staff. The Group HR Director described some of the responses after the eventual de-merger was announced and the rationale for some of the HRIS and HR structural decisions became clearer:

one of the CHRIS support guys said to me after the announcement of the company demerger, the plan to demerger, it now all makes sense, I now understand why we were going down this path - because obviously we couldn't make that public - and I can see why you were doing it, so I'm going to shut up about my grizzling. ..... I couldn't understand why you would want to move it from (interstate) but it now makes sense so I'll get on with life. (HR Director).

By 2011, the Group HR Director had left MFC (with the reduction of 2,500 staff as a result of the sale of a major division a senior Group HR role was no longer required) and the organization was moving into a period of consolidation. The previous Associate HR Director, who had many years of SAP HRIS experience, took over the (reduced) HR Director role. All the previous HRIS team had taken redundancy and the management responsibility for the HRIS was now totally with BIS. While the HRIS still had a largely traditional and transactional role, BIS was beginning to work with HR to look at improved MIS reporting and thus more strategic HR capabilities. However, the focus largely remained on compliance and standardization of HR processes. With the HRIS managed by BIS and an internal transfer pricing mechanism in place, any increased HRIS capabilities were negotiated and typically rejected if any customization of the system was required. On reflection the new HR Director acknowledged the loss of strategic HR functionality in the HRIS but overall this was outweighed by the corporate strategic benefit of having a globally recognized and supported system: 
Also in the future to be able to bring people on - not people, other businesses on, if they so desire to purchase, and bring them into a system .....the reality is that a 25 year legacy system couldn't keep going. So whilst I do think that that was one of the drivers, I still probably get back to the fact that the biggest single driver for this was to de-risk our environment.

Corporate restructuring and the introduction of a new SAP based HRIS produced substantial changes in the relationship between the HRIS and the HR function. The role of BIS, which now controlled the HRIS, was substantially elevated and HR and line managers were required to conform to SAP standards and BIS internal cost accounting requirements, as the following example illustrates.

I guess there was the classic example yesterday with (a request from one of the divisions)... where you, essentially sacrifice two weeks of your salary in order to get two weeks extra leave. It was something that they had in CHRIS. It was stamped out when SAP was introduced because it was too much customisation...also, not many people availed of it so it was one of those things that just got jettisoned. One of the guys - one of the businesses came yesterday and say oh, we've just offered someone an extra two weeks leave to reduce their salary. It came to me and my team. I said okay, it's going to be at least a day's work - which we have a [bill] model for anything that's over half a day. They have to give IT money. They didn't take (the option) ... turned around and said we're not doing it anymore. (BIS executive).

Overall the management of HR and BIS considered the new HRIS a success. While they recognized that elements of the change management process could have been improved, in their view the new HRIS placed the organization in a stronger strategic position for the future.

\section{Discussion and Analysis}


The preceding section presents an overview of the process by which MFC replaced its highly customized legacy HRIS with an HRIS based on the HR modules of its SAP based ERP. One outcome of this implementation was an HRIS which, when compared to legacy system, afforded less strategic functionality. As a result the ability of HR to use the system to execute the needs and demands of line managers and to realize their strategic ambitions was significantly diminished. In this section we argue that this outcome illustrates a specific example of the disruption of a stable actor network which encompassed the legacy HRIS followed by the formation of a new actor network. We argue that viewed through an ANT lens, the strategic ambitions of the HR function were lost in the process of translation.

MFC's highly customized CHRIS based legacy HRIS was part of a stable actor network that had been formed and remained intact and untouched over a number of years. The stability of this actor network and the positive role that it played in enhancing the HR function in MFC was enhanced by the location of the HRIS and the specialized team that worked with it in the HR department. This not only protected the HRIS from other actors, such as BIS and its SAP system, but also ensured that the appropriation and further customization of the system were closely linked to the ambitions of the HR function and its perception of the needs of the business rather than the broader strategic priorities of the business as whole. The stability of the actor network was further reinforced by absence of non-human actors including operating manuals and very limited documentation for the customized HRIS meaning that human actors within the organization wanting to use the HRIS had to rely on members of the HR team and in particular the HRIS Director. In effect the particular role of HR in MFC was inscribed in the HRIS technology. The physical separation of payroll from the HRIS ensured that this non-human actor functioned as a mediator between the actor network associated with the HRIS and other interests in the organization including BIS and finance and their systems.

Our research suggests that a number of major developments disrupted this stable actor network and initiated a process of translation that led to formation of a new network of actors, which included the new SAP based HRIS, new ideas about the purpose of the HRIS and new actors, many of whom were previously excluded from the legacy HRIS actor network. These events included the change in strategic 
direction of the organization, and particularly its desire to implement systems that would facilitate asset disposal and would allow for greater ease in mergers and acquisitions, employment of a new Group HR Director who was charged with cutting costs and preparing the business for restructuring and the threat posed by the impending retirement of the longstanding HRIS Director, who was central to the traditional HRIS actor network. We see here changes in both human actors (the HR Director and the HRIS Director) and in non- human actors including crucially the idea of business risk.

This disruption to the stable actor network surrounding the legacy HRIS resulted in a process of translation that produced a new actor network around a new SAP based HRIS system at MFC. It is possible to identify evidence of each of the four moments of translation identified by Callon (1986) in the case study. First, the introduction of the new actors and changes in the relationships between actors in the traditional actor network introduced a new moment of problematization where the aims of the HRIS and the strategic ambitions of HR were re-evaluated. The formation of evaluation and selection committees to look at what form MFC's HRIS should take in the future, created an opportunity for the Group HR Director, who had previous experience working with SAP and privileged understanding of the broader strategic ambitions of MFC, to bring in the interests of actors that had been largely excluded from the legacy HRIS actor network and to recast or 'frame' the solution the system was designed to provide. While the customized HRIS and its proponents from the HR function were present in these discussions, it allowed a process of interessement that aligned the interests of BIS, Finance and the broader strategic ambitions of MFC in a new actor network built on a redefinition of the problem that the upgrade of the HRIS was to solve. Through the process of interessement the Group HR Director was able to draw on the imperatives of IT standardization and managing the business risk associated with the legacy system to confirm the problematization and encourage BIS, Finance, and MFC more generally to see their interests as being met by the solution of the HRIS upgrade.

Enrollment took place through this definition of the roles of BIS, Finance, and MFC as an organization with a particular strategic future, and through the addition of new actors including the HR modules of SAP, an external consultant with experience 
working with SAP, the relocation of responsibility for the HRIS from HR to BIS and finally the removal of the existing offsite payroll team, aligned to the legacy HRIS, and their replacement with a new team with experience working with SAP located in head office. Key here was the new definition of roles for these actors: BIS replacing HR as the owner of the HRIS, the elimination of the role for the offsite payroll team, and SAP as the primary technology subsuming the HRIS functionality.

During each of these moments not only did the highly customized legacy HRIS have its role in the actor network restricted to historical reporting of data but the HR function progressively lost its previously central role in the new HRIS actornetwork. By the time the translation process was completed and the new actor network was mobilized, HR had lost much of its status as an actor in the network and had instead to work through BIS if it was to derive any strategic value from the new HRIS. Mobilized around the idea of the standardization of the IT system and its location within BIS, the new network was stabilized. The HR functionality that the new SAP based HRIS provided to the business was significantly reduced according to the reports of actors, and, largely excluded from the actor network surrounding it, the ability of HR to realize their strategic ambitions was significantly constrained and rendered contingent on its ability to conform with the requirements of SAP.

\section{Conclusion and contribution}

This research suggests the contribution that actor-network theory can make to the study of the relationship between HRIS and the strategic transformation of HR functions. Set against a widely held expectation in the HR literature, that the current generation of HRIS will help drive the transformation of the HR function from routine compliance towards a more strategic business partnership role, we examined a case study which produced almost completely the opposite results. We demonstrated that in shifting from a highly customized legacy HRIS to one based on the HR modules of an enterprise wide ERP system, MFC lost significant HR functionality and the HR function emerged with diminished ability to contribute strategically. We demonstrated the extent to which this outcome can be explained in terms of the disruption of a 
stable actor-network around the legacy HRIS and the formation of a new actornetwork in which HR played a much less central role. Somewhat ironically, the key initiator of this translation process, which reduced the role of the HR function as a key actor in the HRIS, was the new Group HR Director who was responding to broader perceived strategic ambitions of MFC as a business.

Our paper makes a number of contributions. First, we argue that by moving from the determinist view of technology that largely dominates the HR literature, and employing an approach that sees technology and organization as mutually dependent ensembles, we provide a possible explanation of the apparent paradox of HRIS that we noted earlier. Actor-network theory suggests that the implementation of a sophisticated HRIS technology is unlikely in and of itself to strategically transform the HR function, and indeed as our case study demonstrates might significantly constrain its strategic ambitions. We therefore argue that our findings demonstrate the need for scholars interested in how technology is impacting the role of the HR function to engage more deeply with the contemporary literature on technology and organizations in the IS literature.

We noted earlier that the study of HRIS is a sub-field in the broader literature on e-HRM and that recently there have been calls from e-HRM scholars for analyses that examine stages of IS implementation and the role played by a broader variety of actors in the implementation process (Strohmeier, 2007; Strohmeier \& Kabst, 2009). A further contribution has been to demonstrate that an actor-network framework is able to achieve both of these aims. Through our use of actor-network theory we were able to examine both the impact of social and technical aspects of HRIS implementation, to examine various stages in the HRIS implementation approach and to examine the role played by a broad range of actors, both human and non-human. We would therefore argue that there is considerable scope for greater use of ANT in the broader e-HRM literature.

While our analysis focused on a single case study, it demonstrates that actornetwork theory provides a useful framework for examining differences in the organizational outcomes associated with the adoption of the same HRIS technology 
across organizations, as has been argued in relation to IS implementations more generally (Harty, 2010). In particular, by examining the moments of translation (problematization, interessement, enrollment and mobilization) and the similarities and differences in formation of the actor-networks associated with (ostensibly) the same technology in different cases, we believe HR scholars will be able to generate stronger explanations of the differential impact of HRIS implementation on the HR function. While ANT is not in itself concerned with the success or otherwise of IS implementations, we believe on the basis of the findings presented in this paper, the use of an ANT framework may help HR practitioners identify some key success factors associated with HRIS implementation. It is striking that in the MFC case, HR's strategic ambitions were lost during the formation of a new actor-network and we would argue that a greater understanding of the translation process may assist HR to achieve better outcomes from HRIS implementations.

The final contribution is to broader debates about IS implementation. Our analysis in this paper adds further weight to the efficacy of the application of ANT to the study of IS implementations. There are strong parallels between elements of our case study and Elbanna's analysis of ERP implementations. For example, the decision to centralize payroll in our case during the HRIS implementation process is consistent with her notion of project drift as an inherent feature of ERP implementation (Elbanna, 2008). Furthermore, the role that changes in the strategic priorities of the business and particularly the aim of preparing the business for restructuring and sale provides a good example of the extent to which IS implementations are influenced by other priorities in a multi-project environment (Elbanna, 2010). As such we build on the existing ANT-inspired literature on IS implementations by not only examining the contribution that this framework makes to understanding the implementation process but also by examining the links between IS implementation and the ongoing role played by a key business function (HR) as a result of the implementation. 
References

$<$ Maguire and Hardy on Discourse and Deinstitutionalization the Decline of DDT (2009).pdf>.

Andrade, A. D., \& Urquhart, C. 2010. The affordances of actor network theory in ICT for development research. Information Technology \& People, 23(4): 352-374.

Ball, K. S. 2001. The use of human resource information systems: a survey. Personnel Review, 30(5/6): 677-693.

Barron, M., Chhabra, D., Hanscome, R., \& Henson, R. 2004. Exclusive Panel Discussion: Tips and Trends in HRIS. HR Focus, 81(5): 6-7.

Becker, B. E., Huselid, M. A., \& Ulrich, D. 2001. The HR scorecard: linking people, strategy, and performance Boston: Harvard Business School Press

Bee, F., \& Bee, R. 2002. Managing Information and Statistics London: Chartered Institute of Personnel and Development

Berg, B. L. 2009. Qualitative Research Methods for the Social Sciences (7th ed.). Boston: Allyn \& Bacon

Bondarouk, T., \& Ruël, H. 2012. The strategic value of e-HRM: results from an exploratory study in a governmental organization. The International Journal of Human Resource Management: 1-24.

Bondarouk, T., Ruël, H., \& van der Heijden, B. 2009. e-HRM effectiveness in a public sector organization: a multi-stakeholder perspective. International Journal of Human Resource Management, 20(3): 578590.

Bondarouk, T. V., \& Ruël, H. 2008. HRM systems for successful information technology implementation: evidence from three case studies. European Management Journal, 26(3): 153-165.

Bondarouk, T. V., \& Ruël, H. J. M. 2009. Electronic Human Resource Management: challenges in the digital era. International Journal of Human Resource Management, 20(3): 505-514.

Brown, D. 2002. eHR - victim of unrealistic expectations. Canadian HR Reporter, 15(5): 1.

Callon, M. 1986. Some Elements of a Sociology of Translation: Domestication of the Scallops and the Fishermen of Saint Brieuc Bay. In J. Law (Ed.), Power, Action and Belief: a new Sociology of Knowledge?: 196-233. London: Routledge and Kegan Paul

Cho, S., Mathiassen, L., \& Nilsson, A. 2008. Contextual dynamics during health information systems implementation: an event-based actor-network approach. European Journal of Information Systems, 17(6): 614-630.

Cresswell, K., Worth, A., \& Sheikh, A. 2010. Actor-Network Theory and its role in understanding the implementation of information technology developments in healthcare. BMC Medical Informatics and Decision Making, 10(67).

Dewett, T., \& Jones, G. R. 2001. The role of information technology in the organization: a review, model and assessment. Journal of Management, 27: 313-346. 
Eisenhardt, K. M. 1989. Building Theories from Case Study Research. Academy of Management Review, 14(4): 532-550.

Elbanna, A. 2008. Strategic systems implementation: diffusion through drift. Journal of Information Technology, 23(2): 89-96.

Elbanna, A. 2010. Rethinking IS project boundaries in practice: A multipleprojects perspective. The Journal of Strategic Information Systems, 19(1): 39-51.

Farndale, E., Paauwe, J., \& Hoeksema, L. 2009. In-sourcing HR: shared service centres in the Netherlands. International Journal of Human Resource Management, 20(3): 544-561.

Grant, D., Dery, K., Hall, R., Wailes, N., \& Wiblen, S. 2009. Human Resource Information Systems (HRIS): An Unrealised Potential Annual CIPD Centres' Conference Nottingham, United Kingdom

Haines, V. Y., \& Lafleur, G. 2008. Information technology usage and human resource roles and effectiveness. Human Resource Management, 47(3): 525-540.

Hanseth, O., Ciborra, C., \& Braa, K. 2001. The Control Devolution: ERP and the Side Effects of Globalization. The database for advances in information systems, $32(4)$ : $34-46$.

Harty, C. 2010. Implementing innovation: designers, users and actor-networks. Technology Analysis \& Strategic Management, 22(3): 297-315.

Hendrickson, A. R. 2003. Human Resource Information Systems: Backbone Technology of Contemporary Human Resources. Journal of Labor Research, 24(3): 381-394.

Huselid, M. A. 1995. The Impact of Human Resource Management Practices on Turnover, Productivity, and Corporate Financial Performance Academy of Management Journal, 38(3): 635-672.

Hussain, Z., Wallace, J., \& Cornelius, N. E. 2007. The use and impact of human resource information systems on human resource management professionals. Information \& Management, 44(1): 74-89.

Hyde, A. C., \& Shafritz, J. M. 1977. HRIS: INTRODUCTION TO TOMORROW'S SYSTEM FOR MANAGING HUMAN RESOURCES. Public Personnel Management, 6(2): 70-77.

Kavanagh, M. J., Gueutal, H. G., \& Tannenbaum, S. I. 1990. Human resource information systems: development and application. Boston, Mass: PWS-Kent Publications Co.

Kavanagh, M. J., \& Thite, M. 2009. The Future of HRIS: Emerging Trends in HRM and IT. In M. J. Kavanagh, \& M. Thite (Eds.), Human Resource Information Systems: Basics, Applications, and Future Directions: 409418. California: SAGE Publications Inc.

Kinnie, N. J., \& Arthurs, A. J. 1996. Personnel specialists' advanced use of information technology. Personnel Review, 25(3): 3- 19.

Kovach, K. A., \& Cathcart, J. C. E. 1999. Human Resource Information Systems (HRIS): Providing Business with Rapid Data Access, Information Exchange and Strategic Advantage. Public Personnel Management, 28(2): 275282. 
Latour, B. 1987. Science in Action: How to Follow Engineers and Scientists Through Society. Milton Keynes: Open University Press.

Latour, B. 1991. Technology is Society Made Durable. In J. Law (Ed.), A Sociology of Monstors: Essays on Power, Technology and Domination: 103-131. London: Routledge.

Law, J. 1992. Notes on the Theory of the Actor-Network: Ordering, Strategy and Heterogeneity. Systems Practice, 5(4): 379-393.

Lawler, E., \& Mohrman, S. 2003. HR as a Strategic Partner: What Does It Take to Make It Happen? Human Resource Planning, 26(3): 15-29.

Lawler, E. E., Levenson, A., \& Boudreau, J. W. 2004. HR Metrics and Analytics: Use and Impact. Human Resource Planning, 27(4): 27-35.

Lengnick-Hall, M., \& Moritz, S. 2003. The Impact of e-HR on the Human Resource Management Function. Journal of Labor Research, 24(3): 365-379.

Mahring, M., Holmstrom, J., Keil, M., \& Montealegre, R. 2004. Trojan actornetworks and swift translation: Bringing actor-network theory to IT project escalation studies. Information Technology \& People, 17(2): 210-238.

Martinsons, M. G. 1994. Benchmarking human resource information systems in Canada and Hong Kong. Information \& Management, 26(6): 305-316.

McGrath, K. 2002. The Golden Circle: a way of arguing and acting about technology in the London Ambulance Service. European Journal of Information Systems, 11(4): 251-266.

Miles, M. B., \& Huberman, A. M. 1994. Qualitative data analysis: An expanded sourcebook (2nd ed.). Thousand Oaks, CA: Sage

Morley, M. J., Gunnigle, P., O'Sullivan, M., \& Collings, D. G. 2006. New directions in the roles and responsibilities of the HRM function. Personnel Review, 35(6): 609-617.

Ngai, E. W. T., \& Wat, F. K. T. 2006. Human resource information systems: a review and empirical analysis. Personnel Review, 35(3): 297-314.

Orlikowski, W. J. 2000. Using Technology and Constituting Structures: A Practice Lens for Studying Technology in Organizations. Organization Science, 11(4): 404-428.

Orlikowski, W. J., \& Scott, S. V. 2008. Chapter 10: Sociomateriality: Challenging the Separation of Technology, Work and Organization. The Academy of Management Annals, 2: 433 - 474.

Paauwe, J., \& Boselie, P. 2005. HRM and performance: what next? Human Resource Management Journal, 15(4): 68-83.

Parry, E., \& Tyson, S. 2011. Desired goals and actual outcomes of e-HRM. Human Resource Management Journal, 21(3): 335-354.

Pettigrew, A. M. 1990. Longitudinal Field Research on Change: Theory and Practice. Organization Science, 1(3): 267-292.

Rodon, J., Pastor, J. A., Sese, F., \& Christiaanse, E. 2008. Unravelling the dynamics of IOIS implementation: an actor-network study of an IOIS in the seaport of Barcelona. Journal of Information Technology (Palgrave Macmillan), 23(2): 97-108. 
Ruël, H., Bondarouk, T., \& Looise, J. 2004a. E-HRM: Innovation or Irritation. An Explorative Empirical Study in Five Large Companies on Web-based HRM Management Revue, 15(3): 364-380.

Ruël, H., Bondarouk, T., \& Looise, J. K. 2004b. E-HRM: Innovation or Irritation? An Exploration of Web-Based Human Resource Management in Large Companies Utrecht: Lemma Publishers

Ruta, C. D. 2009. HR portal alignment for the creation and development of intellectual capital. International Journal of Human Resource Management, 20(3): 562-577.

Stake, R. E. 2006. Multiple Case Study Analysis. New York: The Guilford Press.

Strohmeier, S. 2007. Research in e-HRM: Review and implications Human Resource Management Review, 17: 19-37.

Strohmeier, S. 2009. Concepts of e-HRM consequences: a categorisation, review and suggestion. International Journal of Human Resource Management, 20(3): 528-543.

Strohmeier, S., \& Kabst, R. 2009. Organizational adoption of e-HRM in Europe: An empirical exploration of major adoption factors. Journal of Managerial Psychology, 24(6): 482-501.

Tatnall, A., \& Gilding, A. 1999. Actor-Network Theory and Information Systems Research. Paper presented at the 10th Australasian Conference on Information Systems (ACIS), Wellington.

Towers Perrin. 2008. Staying Ahead of Change: Evolving Realities and Expectations in HR Outsourcing. Study of HRO Effectiveness Towers Perrin.

Ulrich, D. 1997. Human resource champions: the next agenda for adding value and delivering results Boston: Harvard Business School Press.

Van de Ven, A. H. 1989. Nothing Is Quite So Practical as a Good Theory. Academy of Management Review, 14(4): 486-489.

Van de Ven, A. H., \& Poole, M. S. 1990. Methods for Studying Innovation Development in the Minnesota Innovation Research Program Organization Science, 1(3): 313-335.

Voermans, M., \& Van Veldhoven, M. 2007. Attitude towards E-HRM: an empirical study at Philips. Personnel Review, 36(6): 887-902.

Walsham, G. 1995. The Emergence of Interpretivism in IS Research. Information Systems Research 6(4): 376-394. 